\title{
The I: A dimensional account
}

\section{Wolfgang Fasching ${ }^{1}$}

Published online: 13 August 2020

(C) The Author(s) 2020

\begin{abstract}
I have a clear idea of what it means that I have experiences in the past or future, and it does not seem to mean that experiences take place that possess certain contentcharacteristics, but simply and irreducibly that $I$ experience them - i.e. that they are, at the time of their occurrence, experientially present to me-, whatever their contents may be. So the central question regarding personal identity is: What is this "I" to whom the experiences are present, and what is the nature of its identity across changing experiences? Following Zahavi, I suggest that the subject is not to be conceived as a merely postulated trans-experiential entity but has its very being in experiential presence itself. Yet the question is how to conceive of this presence. When we understand it as a property or quality of the experiences (as Zahavi seems to do), the problem is that every experience that has ever been experienced possesses this property, and so it cannot account for what it means that some experiences are experienced by me and not some other subject. In contrast, I suggest (following Klawonn's "I-dimension" theory) understanding experiential presence not as a property of the experiences but as a dimension which is able to comprise many experiences and to abide as identical through their change - an idea that can also be found in some formulations of Zahavi's, but which he does not distinguish with the necessary clarity from the quality account.
\end{abstract}

Keywords Personal identity · Subject of experience · Dan Zahavi · Erich Klawonn

\section{Introduction}

The core of the problem of personal identity only comes into view when it is considered from a first-person perspective. When one thinks of other persons and asks under which conditions one regards them as the same persons over time, one might think of things like the sameness of the body, of the fact that the respective person remembers her past experiences, that her experiences and actions are sensibly connected, that the person displays

\section{Wolfgang Fasching}


a certain constancy of personality, and so on. When these various criteria come apart (in real or fictitious cases) this may very well result in puzzle cases where it is unclear whether or not one should still speak of the same person or even - as in such typical personal-identity thought experiments that involve some kind of person-fission - where it is debatable whether one or the other of two later persons should be viewed as identical to an earlier one. Yet these are ultimately what Parfit calls "empty questions" (Parfit 1987, 213 f.): The possible differing answers are grounded not in differing views about what really happens, but only in differing decisions as to the conditions under which one wishes to speak of the same person (i.e. in differing views on how to describe what one agrees is happening). There is nothing overly puzzling about this, and it is not fundamentally different from questions of the identity of other objects, such as clubs or the ship of Theseus. Whether one wishes to speak of the same object after considerable changes have taken place is often simply a matter of taste, arbitrary decision, or convention.

Things radically change, however, as soon as one considers such questions from a first-person perspective ${ }^{1}$ : When $\mathrm{I}$, for example, imagine that $I$ am facing such a fissionprocedure, it seems that the question of whether I will be one or the other of the two future persons - whether I will experience the pain of the one person or the happiness of the other, for example - is a question that must have an unambiguous answer, and one that is not a matter of some arbitrary decision or convention. In other words: It does not seem to be an "empty question". There seem to be definitely two different conceivable possibilities of what may happen which are not just different descriptions of the same states of affairs (cf. e.g. Madell 1981, 99; Klawonn 1991, 6-9; NidaRümelin 2010) - that is, from a first-person point of view I can clearly imagine different courses of events where objectively (from a purely third-personal perspective) everything would be the same (Klawonn 1987, 49). ${ }^{2}$

Hence there is an aspect of personal identity that only comes into sight when we take the perspective of the respective person: the perspective of the experiencing $I$ or subject. The question is then no longer which objectively observable relations between the earlier and the later person hold and what kinds of mental events take place "in" the person in question, but rather whether this person is $m e$, whether his or her experiences are mine. And this seems to be an additional question, irreducible to anything else one can say about those experiences.

For example, I have a perfectly clear idea of what it means that $I$ will experience certain experiences in the future (cf. Nida-Rümelin 2010, 194), and it clearly does not mean that those experiences are associated with a particular objective body or that they possess certain content-characteristics (e.g. that they will contain memories of my present experiences), but simply and irreducibly that $I$ will experience them, whatever their contents may be. It is not a question of the contents of those experiences but of the

\footnotetext{
${ }^{1}$ And as Madell fittingly remarks: "[T] he fundamental error in nearly everything which has been written in this field recently has been the failure to take note of the importance of the first person perspective" (Madell 1981, vii).

${ }^{2}$ Nida-Rümelin rightly remarks that the difference in question in no way only exists for the respective subject, "the difference is an objective difference, a genuine factual difference" (Nida-Rümelin 2012, 170). But the point is that this difference only comes into view when "we use the conceptual resources of self-attribution" (Nida-Rümelin 2010, 198), i.e. for a "first-personal way' of grasping the difference [...] in the sense that grasping the difference requires seeing what the difference is "from your perspective"" (Nida-Rümelin 2012, 169).
} 
to-whom of givenness or experiential presence of those contents. I have this clear idea of what it means that $I$ have experiences, even if I find myself quite unable to articulate what I mean, i.e. to say what the identity of the I consists in. This inability is due simply to the fact that it does not consist in anything else at all, but is irreducible. Experiences being mine consists simply in the fact that I experience them, and in nothing else.

So the core question of personal identity concerns the I or the subject of experience ${ }^{3}$. Admittedly, today it is philosophically quite unfashionable to assume something like an egoentity. Even non-materialistic thinkers are only seldom inclined to posit something like a mental I-substance. There is talk about mental events and about phenomenal or experiential properties of mental events, but hardly ever about an experiencing self; and when the diachronic identity of the person is considered, then - by searching for "criteria" of this sameness - a "reductionist view" of personal identity (as Parfit calls it) is almost always presupposed. The reductionist view of personal identity claims that the diachronic sameness of the person consists not in the identity of an abiding self as an ontologically irreducible element, but rather in nothing other than the identity of the body (which, in turn, is constituted by spatiotemporal continuity) and/or certain unifying relations between the mental events (e.g. relations of memory) (cf. Parfit 1987, 210 f.). To take up the famous Buddhist analogy (from the dialogue between Nagasena and king Milinda): Just as a chariot is nothing over and above its parts and just as its synchronic and diachronic identity consists in nothing other than the way those parts are interrelated - without any need for postulating some additional, mysterious thing-core whose unanalysable constancy would account for the chariot's sameness - the person is nothing over and above her bodily parts and her manifold experiences. Why should the identity of a person be of a fundamentally different nature than that of any other objects?

Yet it is precisely this assimilation of the person to other objects - or to be more precise: to objects tout court - that fails to do justice to the unique ontology of experience. The occurrence of an experience consists in an experiential content being experientially present or given to a respective subject. The existence of my pain, for example, consists in its being experientially present to me and to me only. And permanently changing experiences are present to me, while my I does not change. This has nothing to do with the contents of the experiences, some affinities they might display, but exclusively with the fact that they are present to one and the same experiencing I. So the central question is: What is the nature of the to-whom of this first-personal givenness that belongs to the very being of experience, and what is the nature of its identity?

\section{Subject and first-personal presence}

The I is not a particular experiential content or content-constellation that we could introspectively find (since it is the very to-whom of the givenness of any contents

\footnotetext{
${ }^{3}$ The identity of the person in the literal sense is not quite the same as the identity of the I, insofar as there is more to being a person than just being a subject of experience (see Drummond's contribution to this volume for an illuminative discussion of the nature of the identity of the person in contrast to mere I-identity); yet I think that the I should be a core component of our understanding of what a person is and furthermore that it is what makes the problem of personal identity puzzling in a way the question of the identity of nonexperiencing objects is not.
} 
whatsoever). Yet it also makes no sense, I think, to explain the for-me-ness of experience by positing some hidden, unobservable entity that would be the bearer or owner of the experiences. Our question concerns the phenomenal fact of the unitedness of my experiences in their all being mine, and whatever it is that thus unites them cannot be anything external to the phenomenal sphere itself. As stated above, I know perfectly well what it means that different experiences are experienced by me; this is not something that would be hidden from me - and our question concerns nothing but the nature of this very identity (of what experiences have in common in being experienced by me) and not some unknown causal foundation of it.

For this reason, I have a great deal of sympathy for the thesis - most prominently endorsed by Dan Zahavi - that the I (the "experiential self" as Zahavi calls it) is nothing beyond first-personal presence itself. The for-me-ness of experience does not refer to some entity that would exist in addition to this presence. To be conscious of whatever it is conscious of is the very mode of being of the subject, and there is nothing to be sought beyond that.

Yet what exactly does this mean? The crucial question is how to conceive of this "firstpersonal presence". Zahavi says that the experiential self is to be identified with the "firstpersonal mode of presentation of the experience" (Zahavi 1999, 144) or "the first-personal character of the experiential phenomena" (Zahavi 2014, 18), which he also calls their "quality of mineness" (Zahavi 2005, 124). If we conceive of the self in this way - as a "quality" or "character" of experience, as a "mode" of its givenness - the question immediately arises as to whether this is not a quality that all experiences share. Our leading question is: What makes my experiences mine? What do they have in common in being experienced by me? If the answer is: their first-personal presence (or character), and we understand this as a property of the experiences (a quality they possess or a mode of their givenness), the problem seems to be that this is a characteristic all experiences that have ever been experienced - no matter by whom - have in common. All experiences are, at the moment of their occurrence, "first-personally present", but only some are mine, namely those that are first-personally present to me. So it seems that we are still in need of an individual to-whom of givenness which is presupposed by the feature of first-personal presence and therefore not reduced to it. When Zahavi writes, for example, that "[a]lthough I live through various different experiences, there is [...] something that remains the same, namely, their first-personal character" (Zahavi 2014, 19), it is obvious that this first-personal character as such does not suffice: A past experience is not mine (one that $I$ experienced) simply because it was "first-personally given", rather the common denominator is the firstpersonal givenness to one and the same subject: $m e$. And the question is precisely of what constitutes the sameness of this "me" as the to-whom of givenness.

The obvious reply is that when the I is understood as the quality of first-personal presence, this is not meant in the sense of a property qua universal, but in the sense of the respective instantiation of this property. From the perspective of a respective instance of first-personal presence, the difference between my experience (i.e. the experience which is present in this occurrence of presence) and that of someone else is clear enough, though they all instantiate the general character of first-personal presence (cf. Zahavi 2014, 22 f.).

Fair enough, yet then of course the question arises as to what to do with the diachronic identity of the self. The presence of this experience now and the presence of that experience then are obviously different instances of first-personal presence - 
what, then, makes them experiences of one and the same subject? Zahavi says that it is "the shared mode of givenness that makes two experiences belong to the same subject" (Zahavi 1999, 144; cf. also Zahavi 2011a, 59), that they have a "shared mineness" (Zahavi 2005, 132). What exactly does this mean? As we have seen, it cannot mean that they share the generic character of first-personal presence. But what then?

I think it can mean one of two things (the second meaning will have to wait until later, when I discuss the conception of presence as a dimension). The first reading runs like this: It is not quite right to say that only the respective experience is first-personally present from the perspective of this very experience. Past experiences of the same stream of consciousness retain in some way a first-personal presence in later experiencing. In becoming past, experiences do not simply vanish out of sight, rather, my past experiences, too, are accessible to me in a first-personal mode, as mine. So in this interpretation, the "shared mineness", the "shared mode of givenness", of the past and the present experience which makes them experiences of one and the same subject refers to the first-personal presence that the past experience has now, for the present experience.

Yet this would mean that a past experience is mine only insofar as it is given or accessible to me as mine in my present experiencing. And this amounts to a reductionist account of the identity of the self, or to be more precise, to a version of the Lockean memory-criterion. It amounts to saying that it is not the case that I can remember my past experience because I experienced it, rather it is - the other way around - mine by virtue of my being able to remember it: that "I" had this past experience means nothing other than that I can remember it.

And indeed there are passages where Zahavi seems to say such a thing. For example, he writes: "Whether the same experiential self is present in two temporally distinct experiences depends on [...] whether, say, the past experiential episode is firstpersonally accessible to the present act of recollection" (Zahavi 2014, 72, my emphasis). So what Zahavi is saying here is that the sameness of the self over time is constituted by ("depends on") the memory-accessibility of past experiences in my present experiencing, and the "shared mode of givenness" that constitutes the identity of the subject obviously means that past experiences are given as mine (are firstpersonally present) in my present experience.

To repeat, this amounts to a reductionist theory of personal identity that claims that the identity of the self is constituted by certain relations between the experiences, namely relations of accessibility. This would mean - with regard to the experiential core self that is constitutive of the very being of experience itself - that if I absolutely cannot remember some experiential episode of the past, it was ipso facto not me who experienced it, which strikes me as being highly counterintuitive. ${ }^{4}$

\footnotetext{
${ }^{4}$ Cf. Zahavi 2011b, 329, fn.: "[I]t should be obvious that there are clear limitations to what this notion of self can explain and account for. Consider for instance the case of a man who early in life makes a decision that proves formative for his subsequent life and career. The episode in question is however subsequently forgotten by the person. He no longer enjoys first-person access to it. If we restrict ourselves to what can be accounted for by means of the experiential core self, we cannot speak of the decision being his, as being one he made. $[\ldots]$ However, $[\ldots]$ [...] ]e are more than experiential core selves, we are for instance also narratively configured socialized persons" (my emphasis). So quite obviously the transtemporal identity of the experiencing subject is, according to Zahavi's view, exclusively constituted by first-person accessibility in memory (and our nonetheless remaining the same despite memory-losses is due to our selves qua narrative and social constructs and not a matter of the subject of experience per se).
} 
Are past experiences we no longer have any access to in memory really automatically experiences we did not experience? Whatever one should make of such an account, I do not think that it can qualify as an analysis of what we mean when we think of past and future experiences as experienced by ourselves. By a past experience having been experienced by me, I do not mean that a certain experience took place in the past and that it is now accessible to me (I can make perfect sense of the idea of having had experiences which I cannot remember). And that a future experience will be experienced by me in no way means that an experience will occur which contains memories of my present experience. Think of fear of future pain, for example: What I am afraid of is not that a pain experience will occur that is accompanied by certain memory contents, but simply that $I$ will have to suffer this pain, with or without memories (Madell 1981, 15, 110). As stated above, that $I$ experience experiences is not a matter of their contents (it is not some particular content that ipso facto makes an experience mine), and this includes memories.

In diachronic respect, the question "What makes experiences appear as mine?" seems to me to be different from the question "What makes them mine?" Though with regard to the present experience, givenness-as-mine and mineness coincide, this is not true of past and future experiences: they are not mine by being given to me now, they are mine by virtue of their being experienced by me the moment they occurred or will occur.

So if we claim that there really is nothing but the successive experiences with their respective first-personal presence plus the givenness of (remembered) past and (anticipated) future experiences as mine, this really amounts to an "illusion theory" (Nida-Rümelin 2010, 207 ${ }^{5}$ ) with regard to the persistence of the self: What we permanently think that takes place and what we seem to remember - that we persist as experiencing subjects - is really an illusion. And, to my mind, this is a rather counterintuitive outcome, which we should be quite clear about.

\section{Presence as an experiential dimension}

Yet are we forced into such a reductionist view (which, according to what I have just said, should rather be called an eliminativist view) if we identify the subject with consciousness or experiential presence?

I previously agreed that the I in its most basic sense is nothing other than the experiential presence that is constitutive of the very being of the experiences. When I reflect on my present being qua subject, I find it as the taking-place of experiential presence, of the experiential presence of my present experiences. I do not find myself as some additional entity. And neither am I something I cannot find, which would somehow lie hidden behind or beneath my experiences and their givenness. My I is something absolutely familiar to me, it

\footnotetext{
5 "We have a criterion-free notion of identity across time of conscious individuals [...]. If the illusion theory is correct, then - contrary to what clearly appears to be the case - we cannot use that notion in order to grasp a fact that makes identity statements true. [...] The corresponding real facts about identity of conscious individuals (if there are any) are then constituted by relations that do not play any role in our understanding of what constitutes our continued existence. In all those cases in which we apply or presuppose that criterionfree notion we only seem to grasp a possible state of affairs" (Nida-Rümelin 2010, 207).
} 
exhausts its being in its being conscious of the contents it is conscious of - i.e.: in the experiential thereness of the experiences -, and that means: it is nothing but this consciousness.

Nonetheless, I experience myself as the same consciousness in the change of experiential contents. What does this mean? How can different, succeeding experiences be present in the same presence? This is, we have seen, unintelligible so long as we understand presence as a property each single experience has (so that each experience has its own presence).

However, a second strand is to be found in Zahavi's writings (besides the conceptualization of first-personal presence as a quality of the experiences), a thought he takes up from Erich Klawonn, namely that of first-personal presence as a dimension - for example when he writes that the self is a "ubiquitous dimension of first-personal character that must be distinguished from but can be shared by a multitude of changing experiences" (Zahavi 2014, 72) or refers to "the difference between our singular transitory experiences and the abiding dimension of first-personal experiencing" (Zahavi 2005, 131). Here we find the second possible understanding of what "shared mineness" might mean, and I think this idea of experiential presence or consciousness as a dimension is extremely helpful to understanding the nature of the $\mathrm{I}$ and its diachronic identity.

So why should we understand presence as a dimension, and what does this mean at all? The key question is: Is it correct to say that each experience has its own presence? Actually, I have many experiences right now; a vast manifoldness of phenomenal contents is present to me. And I am aware of their being-present-together. That is, I am not only aware of the presence of this content and of the presence of that content, but of their being present in one presence, in one consciousness. Now the question is how to understand this oneness of consciousness.

If we conceive of presence as a property or quality of the individual phenomenal contents, their being-present-together becomes unintelligible: Each experiential content would have its own presence, and it is quite unclear what we should make of their copresence. The oneness of consciousness does not mean that they share the same property of being present. Two red things are in no way, merely by virtue of sharing the property of redness, united in forming one redness-realm or the like.

One could counter that it is inadequate to regard the many co-present experiential contents as so many single experiences, but rather that they form one total experience with an internal complexity, and it is this total experience that has the quality of first-personal presence. I am totally fine with that, but the question is what makes it one unified experience - and I think nothing on the content-side can do this job (it is not any relation between the contents that would bind them together), rather it is nothing but precisely all those contents being present in one consciousness. And this, to repeat, does not mean that they have the property of presence in common: A complex thing can as a whole have the property of being red, but what makes it one thing in the first place cannot consist in all its parts having the property of redness (different things at different places and times do not become one thing merely by virtue of being red).

Rather, I think that this one consciousness has the character of a dimension (cf. also Henrich 1970, 277). A dimension comprises a manifoldness of items 
within itself, yet it is not the mere summation of these items and its oneness does not come about by some unifying relations between them, rather it is wherein they have their common being and what makes all their interrelations possible in the first place. The one space as the existence-dimension of spatial things is not the summation of these things and its oneness does not come about by virtue of relations between them, since all such relations already presuppose space (i.e. their being-together-in-one-space). And similarly, the oneness of consciousness of many experiential contents cannot come about via any unifying relations between these contents that would somehow glue them together. Non-experiential relations (i.e. merely objectively holding, not themselves experienced relations, say causal relations or relations of similarity) never ipso facto amount to the being-present-in-one-consciousness of these experiences. This would always be an additional fact. Experiential relations, on the other hand, presuppose what they are supposed to constitute, for only what is present in one consciousness can be experienced as standing in relation to each other. The unity of consciousness therefore is primary and non-constituted. ${ }^{6}$ Equally, the one presence is not composed of the presences of the individual contents which would somehow fuse into one presence, just as the one universal space is not composed of the finite spaces it comprises as if they were independently existing parts of it, for those finite spaces can only be understood as existing in space - how should those partial spaces be put together except in the presupposed one space (of which they are dependent moments)? Analogously, it is unintelligible how the presence of this content and the presence of that content should come together except by being aspects of one presence from the very start.

Taken in this sense, the identification of the I with experiential presence does not mean its reduction to a quality of the individual experiences. Rather, it means that the subject exists as the realm of phenomenality in which manifold phenomenal contents have their manifestation. The ontologically prior is this field of consciousness whose oneness is not constituted by any relations between the contents present in it, but rather that wherein they have their very existence qua phenomenal contents. ${ }^{7}$

Perhaps one could ask whether I have not introduced something new in addition to the first-personal presence of the experiential phenomena, namely the dimension of presence in which this presentness of contents happens. But as a matter of fact this is

\footnotetext{
${ }^{6}$ Parfit says that what unites experiences is simply that they are "objects of a single state of awareness" (Parfit 1987,250 ) and that therefore no self that would own them is necessary ("we need not explain this unity by ascribing these experiences to the same person, or subject of experience" (ibid., 251)). Fair enough - yet this sounds as if the experiences existed and were additionally objects of a state of awareness. Yet actually they have their very being in being experienced, i.e. in being present, and it is one presence of many experiences. And this one presence $i s$ the subject that experiences the many experiences so that the unity of the subject is by no means explained by inter-experiential relations, but is the presupposed ontological foundation of the many experiences.

${ }^{7}$ Cf. Klawonn 2009, 84: "The objective dimension is not an individual object (e.g. a physical thing) but the very level or dimension of the existence of objective things, properties, states, processes etc. Analogously, the I-dimension cannot be identified with its 'content' in the form of the experiences of a particular person or being, since it is the level or dimension in which certain experiences are 'exposed' as mine. And just as the contents of the objective dimension may vary without ceasing to be objective, subjective experiences may vary without ceasing to be mine."
} 
nothing additional. The presence-for-me of a particular content is identical to its being manifest in the presence-realm as which I exist. Just as space is not something in addition to the spatiality of the things, the latter rather meaning nothing other than their being situated in space, the being-present of a content is nothing other than its manifestness in the presence-dimension. Its being-in-my-consciousness is its presentness-to-me. The point is simply that the ontologically prior is not the individual contents and their respective presentness but the one presence-dimension of which the individual presentnesses are dependent moments. ${ }^{8}$

\section{The abidance of presence}

Now what does the conception of consciousness as a dimension mean for the question of the diachronic identity of the I? I explained before that if we identify the self with first-personal presence and conceive of the latter as a property or quality of the experiences, the identity of the self over time cannot be thought other than in a reductionist way. Yet if one conceives of consciousness as the dimension in which experiences have their being and which comprises many experiences within itself without being their sum, at least the possibility arises that this dimension itself remains unaffected by the change of the experiences, i.e. that the change of experiences does not ipso facto mean a change of the realm of consciousness in which they take place (but that consciousness is rather the abiding subjectivity-realm in which this very change, this succession of experiential contents, takes place). Then the "shared mineness" of past and present experiences of mine does not mean that the past experiences are now given to me as mine but that they were present in the very same abiding dimension of mineness in which this present experience is now present.

And I think this indeed corresponds to the way our experiential life is given to ourselves. I do not experience one presence-dimension being replaced by a new one, rather I experience a permanent change of what is respectively present, i.e. of what has its manifestation in this presence-dimension. I experience a stream of phenomenal contents, one after the other gaining and losing presence, while the presence-dimension itself in which they have their respective presentness does not change. The streaming of contents takes place in my abiding consciousness. When a content ceases to be present, the presence-dimension itself does not cease to exist, rather the content sinks into the past precisely by being no longer manifested in it.

I think it belongs to the immediate and indubitable evidence of my own I that I experience the presently transpiring streaming of my experience and that this phenomenal streaming which takes place right now takes place in one - namely my -

\footnotetext{
${ }^{8}$ Hence to ask, "Why assume the existence of an I that has the experiences instead of simply saying 'Experiences take place'?" is not so much comparable to asking why one should posit a mysterious, unobservable thing-core in addition to the thing's observable parts instead of just saying that the thing is the assembly of its parts, and that's it (as in the Buddhist chariot-simile), but rather like asking "Where is space? I see this thing, I see that thing, but space is nowhere to be found!". I cannot find space among the spatial things, yet this does not mean that it is an unnecessary metaphysical posit, rather it is that wherein all the finding of spatial things takes place. Analogously, the I is not to be found as one of the experiential contents, yet this does not mean that it is something trans-experiential (a merely postulated entity), rather it is the very experiencing itself wherein they have their presentness.
} 
consciousness. Therefore I would claim that in the very ongoing streaming of my experiences, the oneness of the experiencing $\mathrm{I}$ is immediately and indubitably given as the realm in which this very streaming takes place.

Now perhaps one might reply: Okay, my consciousness is the abiding realm of manifestation of my changing experiences. Yet nonetheless, the question remains as to what the nature of this abidance is. Could it not be that this persisting presence is simply a temporally extended object like any other, having its persisting existence in succeeding temporal objectphases? Then in some sense it would be the case that permanently new presences take place, these momentary presences being continuous with each other in such a way that they can be regarded as together constituting one persisting presence which has in the momentary presences its "temporal parts", as it were, which are indeed numerically distinct from each other. This would mean that the diachronic identity of the I is reducible to the continuity of the consciousness-phases after all (i.e. to the connectedness of the momentary consciousnesses).

Yet I think this way of putting it is inadequate; it does not do justice to the nature of what we are dealing with here. We must keep in mind that consciousness, as I try to conceive it here, is the existence-dimension of the experiences: Consciousness is that wherein they have their very being, their actuality, for presence is the nature of the being-actual of experiences. The actuality-dimension itself does not sink into the past when a phenomenal content ceases to be actual and a new content gains actuality. Rather, something sinks into the past by being no longer present in the actuality-dimension. Thus the presence-dimension is not something that becomes temporarily present and then sinks into the past, but that which gives what is experientially present its respective presence: presentness itself. In this sense, it can be regarded as the "phenomenal nowness", as Klawonn puts it (1991, 258), the now itself of the experiential realm - i.e. not as something that takes place in the now and then loses its nowness, but nothing other than the standing now itself as the abiding "stage" or dimension of existence of coming and going experiential events. ${ }^{9}$

To quote Klawonn with regard to the existence-dimension in general (which he identifies with the standing now): "What may be future or past are things, properties, states of affairs, events etc. [...] but not the field of existence or actuality itself. In other words: this view implies that what is subject to change belongs to the level of specific 'content' or 'innerworldly things', whereas the field of existence in which contents come and go is permanent. It is always now [...]" (Klawonn 2009, 118; cf. Klawonn 1991, 244). And, since experiences have their being in being experientially present, the presence-dimension is the field of existence of the phenomenal realm and therefore, again, nothing other than the phenomenal nowness. "Understood in this way", Klawonn says, "the I-dimension can be characterized as the purely subjective 'is-ness' without pastness or futurity" (Klawonn 1991, 258). The "temporal declination" (Klawonn 2009, 109) - i.e. the coming into existence and ceasing to exist of things - "which obviously applies to phenomenal content, does not apply to the very field of subjectivity in which phenomenal content occurs" (ibid., 120; cf. Klawonn 1991, 256 f.). Similarly, Zahavi writes: "[W]hereas the act can become past and absent, the dimension of experiencing that allows for presence and absence cannot itself become past and absent (for me). Whereas we live through a number of different experiences, the firstpersonal experiencing itself remains as an unchanging dimension” (Zahavi 2000, 67).

\footnotetext{
${ }^{9}$ Comparably, Husserl writes: "[T] $]$ he standing and abiding I is not [...] in the same sense something persisting as something temporal persists, but is [...] the standing and abiding now in the change of its acts" (Husserl 2006, 201 f.). Cf. also Fasching 2012.
} 


\section{Concluding remarks}

So, as we have seen, we find in Zahavi's writings formulations that, in addition to conceiving of the experiential self qua experiential presence as a feature or quality of the experiences, display a certain kinship with the Klawonnian conception of the I as an abiding dimension of experiential presence. Yet while Zahavi declares that he has "sympathy" with this Klawonnian account, he wonders "whether it isn't going beyond what a strictly experiential approach to selfhood can deliver, in so far as it maintains that the experiential self of a present conscious episode can be identical to the experiential self of a past episode even when the past episode is no longer first-personally retrievable or accessible" (Zahavi 2014, 77).

Is that really the case? Have we gone beyond what an experiential account of the nature of the self can deliver? I think this depends on what one understands by such an experiential account. If what Zahavi wishes to say is that an unrememberable past experience is not experientially given to me as mine now, this is trivially true. Such a past experience is obviously not part of what I now experience as my self.

In another sense, I think, the dimensional view of the self is an experiential account. Firstly, the self is in no way posited as some entity beyond experience but is identified with the experiencing - consciousness - itself. In this sense, the realm of the experiential has not been left. Yet, one could counter, the diachronic identity of the self is viewed as something that possibly transcends the evidence of the experientially given. To this it must be said that, secondly, the point is precisely to take seriously the evidence our experiences harbour, namely to stick to what my experience of my diachronic identity tells me, i.e. to stick to as wherein consisting the sameness of myself as an experiencing subject is there for me. In memory, a past experience is given to me as having been experienced by me, and this "having been experienced by me" is not given to me as identical to "being given to me now" or "being accessible to me now". To say those two things are the same amounts to not doing justice to the intentional sense of the memory-experience. This sense is not "this past experience was experienced by me because and insofar as it is given or accessible to me now", but simply that in the very same experiential dimension as which I, as a subject, abidingly exist, this other experience was present back then. It is given to me as having been experienced by me totally independently of this present givenness or its present accessibility.

Of course, this inherent claim of our memory could in principle be an illusion. Yet my point is (a) that when consciousness is conceived of as the dimension of the presence of the experiences (instead of a property of them), as suggested here, consciousness does not necessarily change with the phenomenal contents so that the testimony of our memoryexperience could be veridical, and (b) that we immediately experience in the ongoing streaming of the phenomenal contents the "standing" of this experiential dimension. Taken together, this gives us good reason, I believe, to take the evidence of memory by its word, so to speak: namely that I existed back then and had those experiences, and that this is not due to the experiences' present accessibility to me, but simply to their having been present in the same presence-dimension as which I exist right now and whose abidance I permanently experience.

Availability of data and material Not applicable.

Code availability Not applicable.

Funding information Open access funding provided by University of Vienna. 


\title{
Compliance with ethical standards
}

\author{
Conflict of interest Not applicable.
}

Open Access This article is licensed under a Creative Commons Attribution 4.0 International License, which permits use, sharing, adaptation, distribution and reproduction in any medium or format, as long as you give appropriate credit to the original author(s) and the source, provide a link to the Creative Commons licence, and indicate if changes were made. The images or other third party material in this article are included in the article's Creative Commons licence, unless indicated otherwise in a credit line to the material. If material is not included in the article's Creative Commons licence and your intended use is not permitted by statutory regulation or exceeds the permitted use, you will need to obtain permission directly from the copyright holder. To view a copy of this licence, visit http://creativecommons.org/licenses/by/4.0/.

\section{References}

Fasching, W. (2012). Ich und Jetzt. Von der Ständigkeit der Erlebnisgegenwart. In R. Esterbauer \& M. Ross (Eds.), Den Menschen im Blick. Phänomenologische Zugänge (pp. 505-526). Königshausen \& Neumann: Würzburg.

Henrich, D. (1970). Selbstbewußtsein: Kritische Einleitung in eine Theorie. In R. Bubner, K. Cramer, \& R. Wiehl (Eds.), Hermeneutik und Dialektik (Vol. 1, pp. 257-284). Tübingen: Mohr.

Husserl, E. (2006). Späte Texte über Zeitkonstitution (1929-1934). Die C-Manuskripte. Ed. by D. Lohmar. Dordrecht: Springer (Husserliana Materialien VIII).

Klawonn, E. (1987). The "I": On the ontology of first personal identity. Danish Yearbook of Philosophy, 24, $43-75$.

Klawonn, E. (1991). Jeg'ets ontologi. En afhandling om subjektivitet, bevidsthed og personlig identitet. Odense: Odense Universitetsforlag.

Klawonn, E. (2009). Mind and death. A metaphysical investigation. Odense: University Press of Southern Denmark.

Madell, G. (1981). The identity of the self. Edinburgh: Edinburgh University Press.

Nida-Rümelin, M. (2010). An argument from transtemporal identity for subject-object dualism. In R. C. Koons \& G. Bealer (Eds.), The waning of materialism (pp. 191-211). Oxford: Oxford University Press.

Nida-Rümelin, M. (2012). The non-descriptive individual nature of conscious beings. In G. Gasser \& M. Stefan (Eds.), Personal identity: complex or simple? (pp. 157-176). Cambridge: Cambridge University press.

Parfit, D. (1987). Reasons and persons. Oxford: Oxford University Press.

Zahavi, D. (1999). Self-awareness and alterity. A phenomenological investigation. Evanston, IL: Northwestern University Press.

Zahavi, D. (2000). Self and consciousness. In D. Zahavi (Ed.), Exploring the self. Philosophical and psychopathological perspectives on self-experience (pp. 55-74). John Benjamins: Amsterdam/ Philadelphia.

Zahavi, D. (2005). Subjectivity and selfhood. Investigating the first-person perspective. Cambridge, MA/ London: MIT Press.

Zahavi, D. (2011a). The experiential self. Objections and clarifications. In M. Siderits, E. Thompson, \& D. Zahavi (Eds.), Self, no self? Perspectives from analytical, phenomenological, and Indian traditions (pp. 56-78). Oxford: Oxford University Press.

Zahavi, D. (2011b): Unity of consciousness and the problem of the self. In S. Gallagher (Ed.), The Oxford handbook of the self (p. 316-335). Oxford: Oxford University press.

Zahavi, D. (2014). Self and other. Exploring subjectivity, empathy, and shame. Oxford: Oxford University Press.

Publisher's note Springer Nature remains neutral with regard to jurisdictional claims in published maps and institutional affiliations. 